\title{
EFFECTIVENESS OF ORAL ERYTHROMYCIN VERSUS TOPICAL MODALITIES IN THE TREATMENT OF PITYRIASIS ROSEA- A PROSPECTIVE COMPARATIVE THERAPEUTIC TRIAL
}

\author{
Anza Khader1, Mohamed Shaan², Sarita Sasidharan Pillai ${ }^{3}$, Najeeba Riyaz 4 , Biju George 5 \\ ${ }^{1}$ Associate Professor, Department of Dermatology, Government Medical College, Kozhikode. \\ ${ }^{2}$ Associate Professor, Department of Medicine, Government Medical College, Kozhikode. \\ ${ }^{3}$ Associate Professor, Department of Dermatology, Government Medical College, Kozhikode. \\ 4 Professor and Former HOD, Department of Dermatology, Government Medical College, Kozhikode. \\ ${ }^{5}$ Assistant Professor, Department of Social and Preventive Medicine, Government Medical College, Kozhikode.
}

\section{ABSTRACT}

\section{BACKGROUND}

Pityriasis rosea is a common acute inflammatory dermatosis affecting all age groups. Various treatment modalities like emollients, topical steroids, UV-light, oral erythromycin and high-dose acyclovir have been used in the management of the disease with varying results. The efficacy of systemic treatment over topical therapy is not known beyond doubt.

\section{MATERIALS AND METHODS}

Clinically diagnosed cases of Pityriasis rosea were alternately allotted into 3 treatment groups. One group received emollients, second group moderately potent topical steroids for twice daily application and third group oral erythromycin stearate daily $(1 \mathrm{~g}$ in 4 equally divided doses in adults for 2 weeks and $25-40 \mathrm{mg} / \mathrm{kg}$ in 4 divided doses in children). All patients were evaluated clinically after 2 weeks for improvement in symptoms, increase or decrease of erythema and scaling and appearance of new lesions. Chi-square test was done for statistical analysis.

\section{RESULTS}

Out of 140 patients in the present series, 46 received emollients, 47 topical steroids and 47 erythromycin. 19.6\% showed complete response with emollients, $48.9 \%$ showed a complete response with topical steroids and $57.4 \%$ with erythromycin. Efficacy of topical steroids was 1.58 times and that of erythromycin 1.89 times than emollients. However, efficacy of erythromycin over topical steroids was not statistically significant.

\section{CONCLUSION}

Our study demonstrates efficacy of erythromycin and topical steroids over emollients in the treatment of Pityriasis rosea. However, erythromycin is found to have no added benefit over topical steroids.

\section{KEYWORDS}

Pityriasis rosea, Emollients, Topical Steroids, Erythromycin.

HOW TO CITE THIS ARTICLE: Khader A, Shaan M, Pillai SS, et al. Effectiveness of oral erythromycin versus topical modalities in the treatment of pityriasis rosea- a prospective comparative therapeutic trial. J. Evolution Med. Dent. Sci. 2017;6(32):2627-2631, DOI: $10.14260 /$ Jemds $/ 2017 / 567$

\section{BACKGROUND}

Pityriasis rosea (PR) is an acute or subacute inflammatory dermatosis, first described by Camille Melchoir Gibert in 1860.[1] Even after two centuries, the definitive aetiology and treatment of PR is uncertain. Various treatment modalities like topical steroids,[1] UV-light,[2] oral erythromycin[3] and high-dose acyclovir[4] have been reported to be useful in the management of the disease with varying results. Oral dexchlorpheniramine, a sedative histamine- 1 antagonist is known to exert non-specific anti-itching effects in PR. Chuh et al in their systematic review have recommended randomised controlled trials to investigate the treatments for PR that are commonly used by dermatologists like topical steroids and emollients.[5]

Financial or Other, Competing Interest: None

Submission 16-03-2017, Peer Review 09-04-2017,

Acceptance 15-04-2017, Published 20-04-2017.

Corresponding Author:

Dr. Anza Khader,

"MASKAN," 5/1986 B,

Rajiv Nagar Colony, Calicut-673004.

E-mail:anzashaan@gmail.com

DOI: $10.14260 /$ jemds/2017/567
Due to the prevailing discrepancies regarding the efficacy of both systemic and topical modalities, we performed the study to know the effect of erythromycin in the treatment of PR and its efficacy in comparison with two other common topical therapeutic modalities, topical steroids and emollients.

\section{MATERIALS AND METHODS}

All clinically diagnosed cases of PR attending outpatient department of Dermatology at a tertiary centre during one year formed the material for this study. This was an openlabel, non-randomised parallel group clinical trial. A sample size required was calculated as 41 in each group with an alpha error of $5 \%$ and a power of $80 \%$ to demonstrate $30 \%$ cure rate with erythromycin and topical steroids and 20\% cure with emollient. Diagnosis was based on clinical grounds, i.e. morphology and distribution of the lesions, keeping in mind the atypical variants. An informed consent was taken from each patient included in the study. Those patients who took any modality of treatment and those with a history of intolerance to erythromycin were excluded from the study. An Ethics Committee approval was obtained from the institution for conducting the study. 
A detailed history was taken with particular reference to the duration of signs and symptoms, presence of pruritus, history of prodromal symptoms, history of drug intake and personal or family history of atopy. A detailed clinical examination was made. Routine blood examination and VDRL test was done in all patients, skin biopsy only in selected patients presenting with atypical pattern.

A total of 140 patients who satisfied the inclusion and exclusion criteria were recruited and alternately allotted into 3 treatment groups with allocation ratio 1:1:1. The first group received emollient liquid paraffin for local application after bath, second group moderately potent topical steroid betamethasone dipropionate $0.05 \%$ cream for twice daily application and third group oral erythromycin stearate daily $1 \mathrm{~g}$ in 4 equally divided doses in adults for 2 weeks and 25 $40 \mathrm{mg} / \mathrm{kg}$ in 4 divided doses in children.

All patients were evaluated clinically after 2 weeks for improvement in symptoms, increase or decrease of erythema and scaling and appearance of new lesions.

Statistical analysis was performed by means of chi-square test for the differences in proportion. Baseline characteristics of various treatment groups were compared using the MannWhitney U test. Three drugs were compared with each other and in order to adjust for the inflation in alpha error $\mathrm{p}$ value was adjusted using a Bonferroni technique. The level of significance was kept as 0.05 and the software used was SPSS 18.

\section{Responses were Categorised into 3 groups,}

1. Complete Response- Erythema and scaling in existing patches disappeared, no new lesions appeared.

2. Partial Response- Some decrease in erythema and scaling in the existing patches or few new lesions appeared.

3. No Response- If lesions did not show any regression or if new lesions appeared.

Baseline characteristics of various treatment groups were compared using the Kruskal-Wallis test. Statistical analysis was performed by means of chi-square test for the differences in proportion. The three treatments were compared with each other and in order to adjust for the inflation in alpha error, $p$ value was adjusted using a Bonferroni technique. The level of significance was kept as 0.05 .

\section{RESULTS}

Figure 1 shows the flow diagram of the study. During one year period, 140 cases of PR who attended the outpatient department were enrolled into the study. Highest incidence was found in the age group $11-20(37.8 \%) ; 13.5 \%$ of the patients were under the age of 10 years and $3.5 \%$ of patients above 50 years. Out of the 140 cases, 74 were males $(52.8 \%)$ and $66(47.1 \%)$ were females.

108 patients out of $140(77.1 \%)$ had pruritus. 45 patients (41.6\%) had moderate-to-severe itching. The classical papulosquamous lesions occurred in 114 (81.43\%), erythema-multiforme like lesions in 9 , papules in 8 , eczematous lesions in 6, pustules in 2 and lichenoid lesions in a single patient (Fig. 2, 3, 4, 5a, 5b). Herald patch was seen only in 54 (38.5\%). Routine blood examination showed normal results in all. No significant difference was observed with respect to age, sex, average duration of the disease and ESR between the three treatment groups [Table 1].

Comparing the response to topical steroids to that of emollients, the likelihood of better response was 1.58 times more with topical steroids than with emollients [Table 2]. Comparing the response to erythromycin to that of emollients, the likelihood of better response was 1.89 times more with erythromycin than with emollients [Table 3]. However, there was no significant difference in complete response to erythromycin and tropical steroids [Table 4]. No major side effects were observed in any of the three groups.

\begin{tabular}{|c|c|c|c|c|}
\hline Variables & Emollients & $\begin{array}{c}\text { Topical } \\
\text { Steroids }\end{array}$ & $\begin{array}{c}\text { Erythro- } \\
\text { mycin }\end{array}$ & $\begin{array}{c}\mathbf{p} \\
\text { value }\end{array}$ \\
\hline Mean age & 23.5 & 21.4 & 25.9 & 0.15 \\
$\left(12.8^{*}\right)$ & $\left(13.5^{*}\right)$ & $\left(13.5^{*}\right)$ & \\
\hline $\begin{array}{c}\text { Sex: Male } \\
\text { Female }\end{array}$ & 22 & 28 & 24 & 0.5 \\
\cline { 2 - 4 } $\begin{array}{c}\text { Duration of } \\
\text { Disease } \\
\text { (Days) }\end{array}$ & 17.37 & 19 & 23 & \\
\hline ESR & $\left(19.53^{*}\right)$ & $\left(16.28^{*}\right)$ & 14.33 & 0.42 \\
& 20.38 & $\left.15.65^{*}\right)$ & \\
$\left(20.4^{*}\right)$ & $\left(13.2^{*}\right)$ & 16.44 & 0.48 \\
& \multicolumn{4}{|c|}{ Table 1. Baseline Characteristics } \\
of Three Treatment Groups \\
\hline
\end{tabular}

*Standard Deviation

\begin{tabular}{|c|c|c|}
\hline Treatment & $\begin{array}{c}\text { Partial/No } \\
\text { Response }\end{array}$ & $\begin{array}{c}\text { Complete } \\
\text { Response }\end{array}$ \\
\hline Emollients & $37(80.4 \%)$ & $9(19.6 \%)$ \\
\hline Topical Steroids & $24(51.1 \%)$ & $23(48.9 \%)$ \\
\hline \multicolumn{2}{|r|}{ Table 2. Comparison between Response } \\
to Topical Steroids and Emollients
\end{tabular}

$\mathrm{P}=0.018$, Relative risk $=1.58,95 \%$, Confidence Interval $=1.15$ -2.16 .

\begin{tabular}{|c|c|c|}
\hline Treatment & $\begin{array}{c}\text { Partial/ } \\
\text { No Response }\end{array}$ & $\begin{array}{c}\text { Complete } \\
\text { Response }\end{array}$ \\
\hline Emollients & $37(80.4 \%)$ & $9(19.6 \%)$ \\
\hline Erythromycin & $20(42.5 \%)$ & $27(57.4 \%)$ \\
\hline \multicolumn{2}{|r|}{ Table 3. Comparison between Response } \\
to Erythromycin and Emollients \\
\hline
\end{tabular}

$\mathrm{p}=0.0012$, Relative risk $=1.89,95 \%$, Confidence interval $=$ $1.32-2.71$.

\begin{tabular}{|c|c|c|c|c|}
\hline Treatment & $\begin{array}{c}\text { Partial/ } \\
\text { No } \\
\text { Response }\end{array}$ & $\begin{array}{c}\text { Complete } \\
\text { Response }\end{array}$ & $\begin{array}{c}\text { RR } \\
\mathbf{( 9 5 \% ,} \\
\text { CI) }\end{array}$ & $\begin{array}{c}\text { p } \\
\text { value }\end{array}$ \\
\hline Emollients & $\begin{array}{c}37 \\
(80.4 \%)\end{array}$ & $9(19.6 \%)$ & $1^{\mathrm{a}}$ & \\
\hline $\begin{array}{c}\text { Topical } \\
\text { Steroids }\end{array}$ & $\begin{array}{c}24 \\
(51.1 \%)\end{array}$ & $23(48.9 \%)$ & 2.5 & 0.005 \\
\hline $\begin{array}{c}\text { Erythromy } \\
\text { cin }\end{array}$ & $\begin{array}{c}20 \\
(42.5 \%)\end{array}$ & $27(57.4 \%)$ & $\begin{array}{c}2.9 \\
(1.6-5.5)\end{array}$ & $<0.001$ \\
\hline \multicolumn{5}{|c|}{ Table 4. Comparison between Response } \\
to Erythromycin and Topical Steroids \\
\hline \multicolumn{6}{|c}{}
\end{tabular}

a- Emollient group was considered as the reference group for risk calculation and $\mathrm{p}$ value calculations. RR- Relative risk, CIConfidence Interval. 


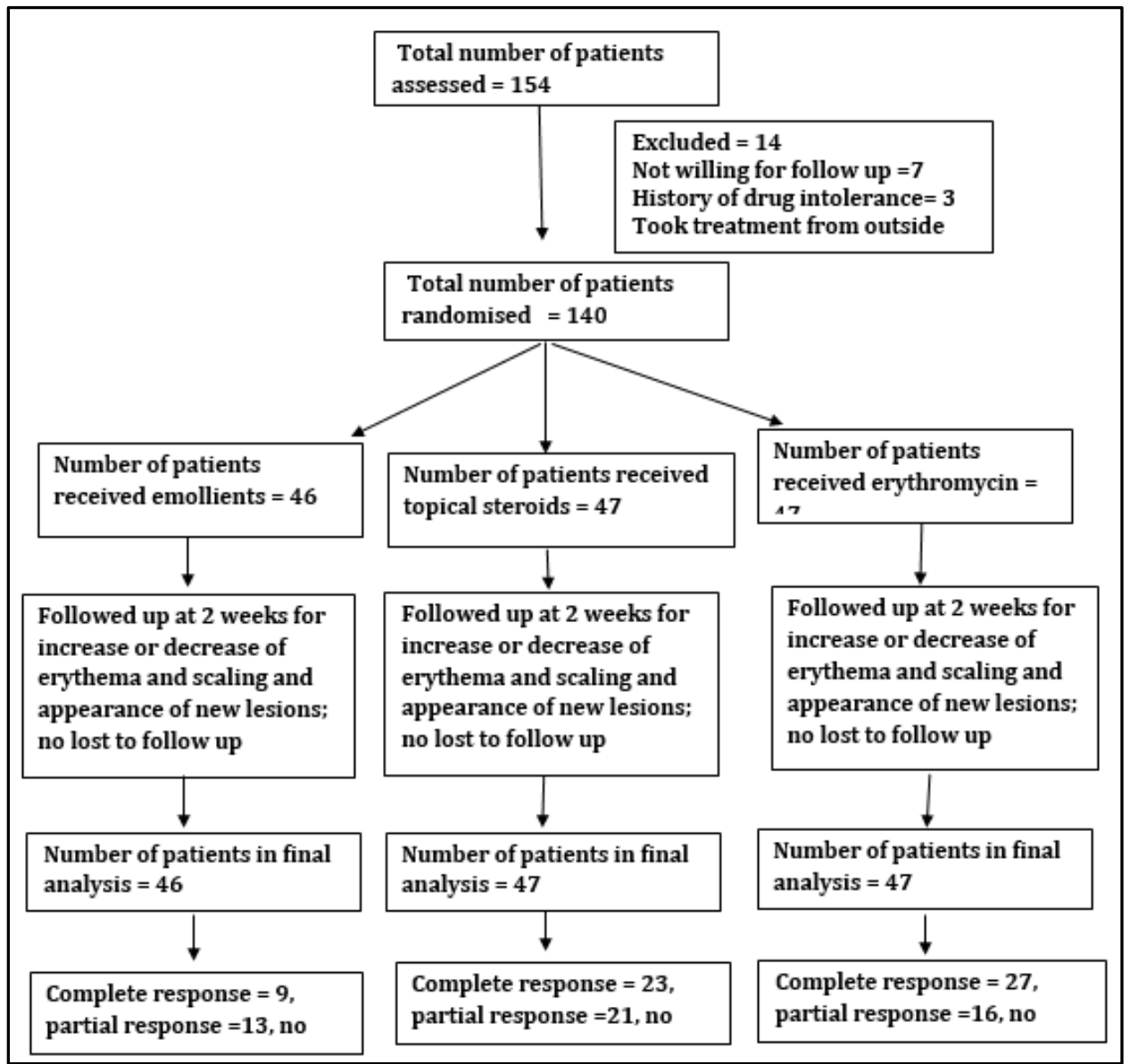

\section{Figure 1}

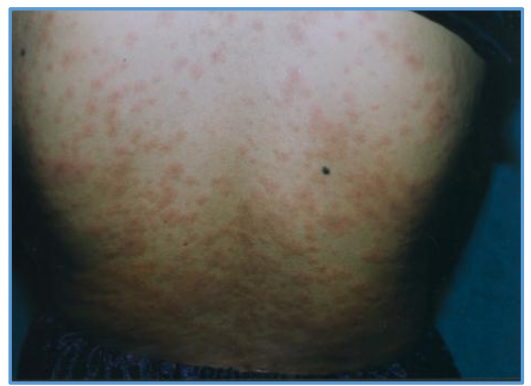

Figure 2. Erythematous Papules and Plaques over Back

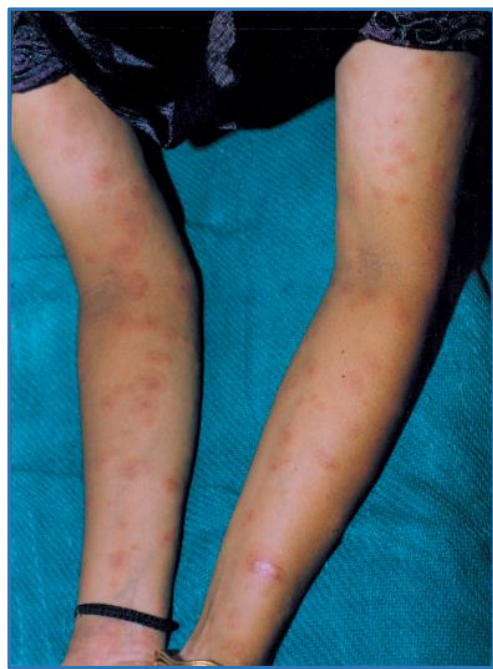

Figure 3. Erythema multiforme like Lesions on Arm and Forearm

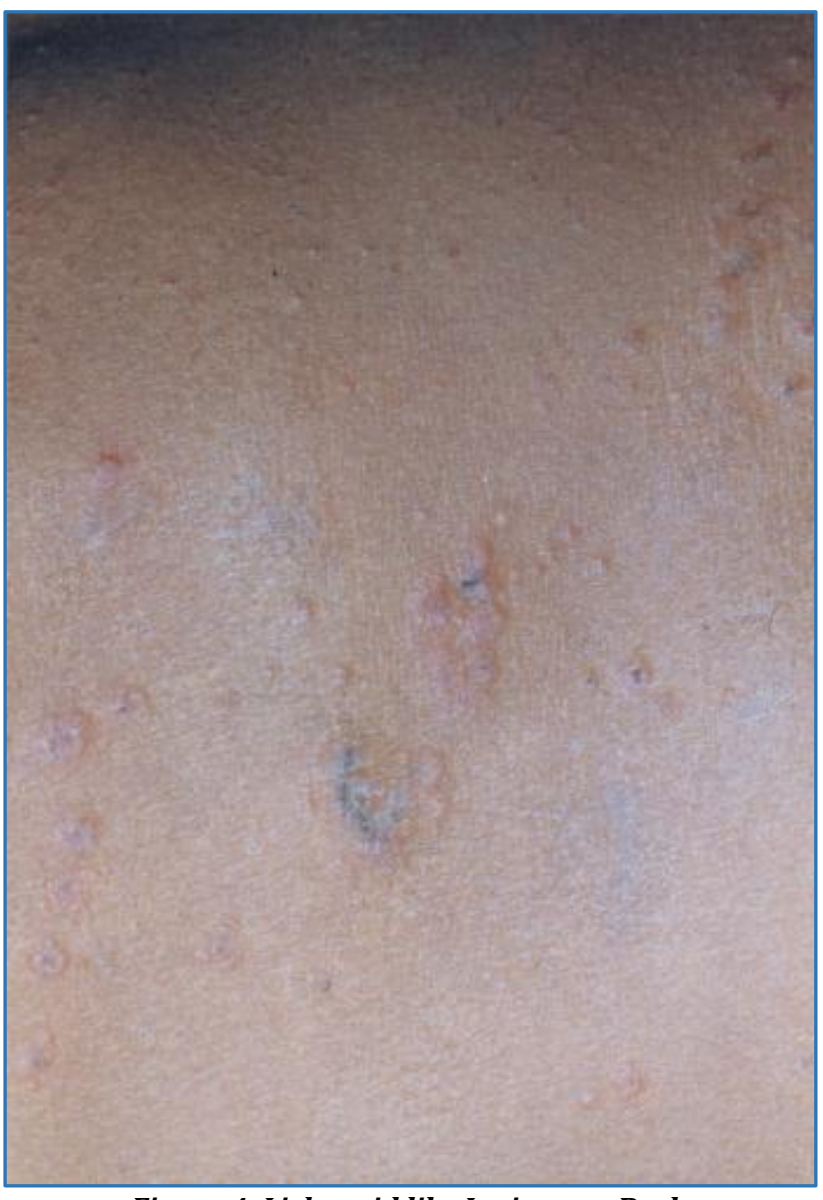

Figure 4. Lichenoid like Lesions on Back 


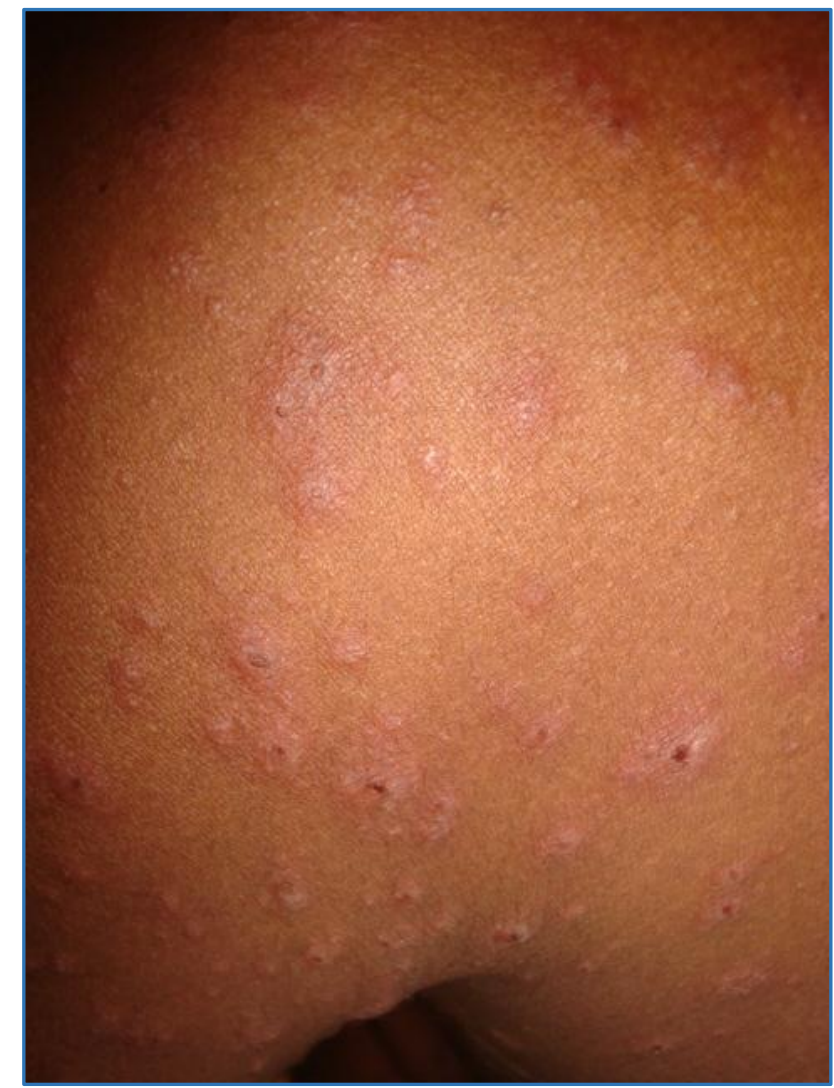

Figure 5a. Erythematous and Crusted Papules and Plaques over Arm

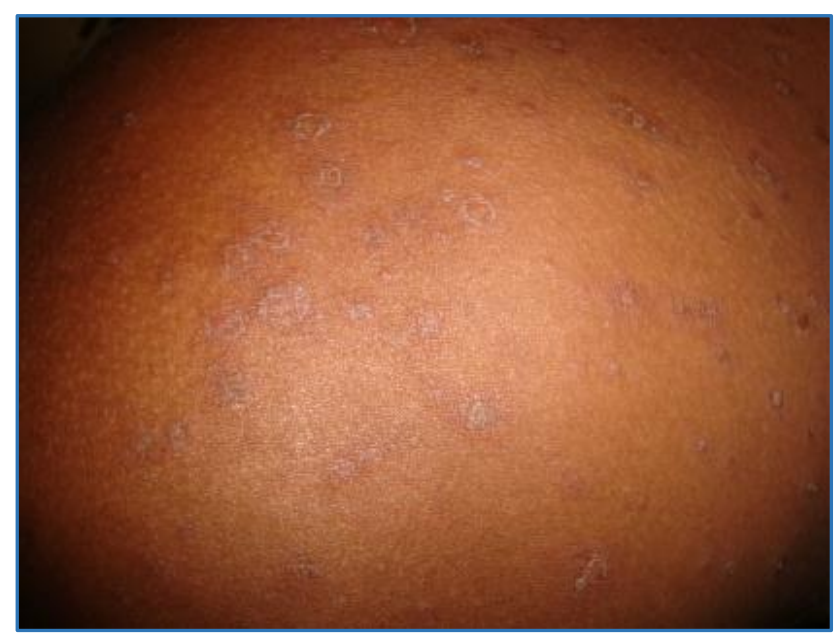

Figure 5b. Lesions subsiding after Treatment

\section{DISCUSSION}

Most cases of Pityriasis rosea (PR) occur between ages of 10 and 35 years and is rare in very young and very old.[6] Present study revealed $59.2 \%$ patients in the age group $11-30$ agreeing to previous studies.

Contrary to the belief of equal sex predilection, Indian studies by Mandal and Dutta found a striking predominance among males, ${ }^{[7,8]}$ as seen in ours. In the present study, pruritus was present in more than $70 \%$ of which $41.6 \%$ had moderate-to-severe itching. Sweating aggravates itching and in tropical areas this may contribute to high incidence of itching. Present study is agreeing to the fact that PR is an "itchy" dermatosis and not an asymptomatic problem. Herald patch was absent in a majority of our patients akin to other Indian studies, which report a low incidence (17.5\%).[7]
However, there are conflicting reports of high incidence of herald patch of about $80 \% .{ }^{[9]}$

Out of 140 patients in the present series 46 received emollients, 47 topical steroids and 47 were given erythromycin. Among the patients treated with emollients 9 showed complete response, whereas 37 showed partial/no response. In contrast the patients treated with topical steroids, 23 showed a complete response and 24 showed partial/no response. There was a significant increase in the number of patients who had complete response to topical steroids.

Topical steroids are recommended as treatment in PR,[1,5] though they do not decrease the incidence of new eruptions and do not cause rapid subsidence of post-inflammatory hypopigmentation. Moderately potent topical steroids are known to decrease inflammation by suppressing migration of polymorphonuclear leucocytes and reversing capillary permeability. It also affects production of lymphokines and has an inhibitory effect on Langerhans cells. Since PR is known to have an immunological basis as reflected by epidermotropism of mononuclear cells of helper/inducer $\mathrm{T}$ cells and Langerhans cells, the dermatosis may respond to topical steroids.[10]

Oral erythromycin stearate $1 \mathrm{gm}$ in four equally divided doses was found to clear PR in two weeks with complete response in $73.33 \%$ in the treatment group and none in the placebo group. ${ }^{[3]}$ In the present study out of 47 patients who received oral erythromycin 27 showed complete response, whereas 20 patients had only partial/no response. In the present study, all patients tolerated erythromycin without any major side effects.

Response to erythromycin has led to the suggestion that PR may be caused by an infectious agent sensitive to erythromycin. However, failure to associate PR with Chlamydia pneumoniae, Chlamydia trachomatis, Legionella pneumophila, Legionella longbeachae, Legionella micdadei or mycoplasma pneumoniae has led to the thought that antiinflammatory and immunomodulatory effect might contribute to the effect of erythromycin in PR more than its anti-microbial effect.[11] Erythromycin directly influences phagocyte and lymphocyte function as well as chemotaxis. They are known to exert immunopharmacological effects on the basis of structure-activity relationships independent of anti-bacterial activity.[12]

Study by Sharma et al showed a successful resolution of PR rash with erythromycin.[3] A randomised double-blind control trial by Villarma et al also found erythromycin to be effective.[5] A double-blind placebo controlled clinical trial from Iran concluded azithromycin, a related macrolide antibiotic to be effective in treating PR.[13] However, certain other studies reveal contradictory reports of ineffectiveness of macrolides.[14,15,16]

Present study has done an attempt to know the efficacy of erythromycin and to compare it with that of topical steroids and emollients, which was not tried in any of the previous studies. 27 patients who received erythromycin showed complete response in comparison to 23 patients of topical steroid group and 9 in the emollient group. Efficacy of erythromycin when compared to emollients was found to be statistically significant.

However, the effect of erythromycin over topical steroids is not statistically significant. 


\section{CONCLUSION}

To conclude, systemic erythromycin though found to be effective than emollients in the treatment of PR, its efficacy is just the same as moderately potent topical steroids. The usage of systemic agent in a condition where topical modality is as effective as systemic therapy needs to be justified.

\section{REFERENCES}

[1] Parsons JM. Pityriasis rosea - an update: 1986. J Am Acad Dermatol 1986;15(2 Pt 1):159-67.

[2] Arndt KA, Paul BS, Stern RS, et al. Treatment of pityriasis rosea with UV radiation. Arch Dermatol 1983;119(5): 381-2.

[3] Sharma PK, Yadav TP, Gautam RK, et al. Erythromycin in pityriasis rosea: a double blind, placebo-controlled clinical trial. J Am Acad Dermatol 2000;42(Pt 1): 241-4.

[4] Drago F, Vecchio F, Rebora A. Use of high- dose acyclovir in pityriasis rosea. J Am Acad Dermatol 2006;54(1):82-5.

[5] Chuh AA, Dofitas BL, Comisel GG, et al. Interventions for pityriasis rosea. Cochrane Database Syst Rev 2007;2:CD005068.

[6] Chuang T, Ilstrup DM, Perry HO, et al. Pityriasis rosea in Rochester, Minnesota, 1969 to 1978. A 10-year epidemiologic study. J Am Acad Dermatol 1982;7(1):80-9.

[7] Mandal SB, Dutta AK. A clinical study of pityriasis rosea. Ind J Dermatol 1972;17(4):100-5.
[8] Sharma L, Srivastava K. Clinicoepidemiological study of pityriasis rosea. Indian J Dermatol Venereol Leprol 2008;74(6):647-9.

[9] Zawar V, Jerajani H, Pol R. Current trends in pityriasis rosea. Expert Rev Dermatol 2010;5(3):325-33.

[10] Onzalez E. Pityriasis rosea. In: Arndt, Le Boit, Robinson, et al. eds. Cutaneous medicine and surgery an integrated programme in dermatology. $1^{\text {st }}$ edn. Saunders 1996:218-21.

[11] Chuh AA, Chan HH. Prospective case control study of chlamydia, legionella, mycoplasma infections in patients with pityriasis rosea. Eur J Dermatol 2002;12(2):170-3.

[12] Brinkmeier T, Frosch PJ. Oral antibiotics with antiinflammatory/immunomodulatory effects in the treatment of various dermatosis. Hautarzt 2002;53(7): 456-65.

[13] Ehsani AH, Toosi S, Noormohamadpour P, et al. Azithromycin in pityriasis rosea: a double blind placebo controlled clinical trial. Iran J Dermatol 2008;11(46):143-6.

[14] Bukhari IA. Oral erythromycin is ineffective in the treatment of pityriasis rosea. J Drugs Dermatol 2008;7(7):625.

[15] Amer A, Fischer H. Azithromycin does not cure pityriasis rosea. Pediatrics 2006;117(5):1702-5.

[16] Rasi A, Tajziehchi L, Savabi-Nasab S. Oral erythromycin is ineffective in the treatment of pityriasis rosea. J Drugs Dermatol 2008;7(1):35-8. 